América sin nombre, n. ${ }^{\circ} 22$ (2017) 125-135

DOI 10.14198/AMESN.2017.22.12

ISSN: 1577.3442 / eISSN: 1989-9831

Fecha de recepción: 02/06/2017

Fecha de aceptación: 30/06/2017
Puede citar este artículo como:

Estrada, Oswaldo. «Utopías libertarias y sueños de igualdad: Mario Vargas Llosa y Flora Tristán». El cuento hispanoamericano del siglo XXI. Agustín Prado Alvarado (coordinador). América sin Nombre, 22 (2017): 125-135, DOI: 10.14198/AMESN.2017.22.12

Link para este artículo: http://dx.doi.org/10.14198/AMESN.2017.221.12

\title{
Utopías libertarias y sueños de igualdad: Mario Vargas Llosa y Flora Tristán
}

\author{
Libertarian utopias and dreams of equality: \\ Mario Vargas Llosa and Flora Tristán
}

\author{
Oswaldo Estrada* \\ University of North Carolina at Chapel Hill
}

\section{Resumen}

Este artículo analiza la reconstrucción ficcional que Mario Vargas Llosa realiza de Flora Tristán, tomando en cuenta diversas rearticulaciones histórico-literarias de los siglos XIX y XX. A diferencia de otras escrituras con respecto a la famosa escritora franco-peruana, la de Vargas Llosa en El paraiso en la otra esquina (2003) articula un mundo posible y coherente desde una perspectiva alternativa y disidente, sin la religiosidad, el fervor nacionalista o la actitud paternalista que hallamos en otros trabajos sobre Flora Tristán, la intelectual que luchó por alcanzar una utopía socialista de igualdad para las mujeres y los obreros oprimidos. Para realizar este análisis de reconstrucción histórica, el crítico analiza el ensamblaje feminista de Flora Tristán en la novela de Vargas Llosa, a la luz de varios de sus ensayos con respecto al mundo de la ficción y el poder político de la literatura.

Palabras clave: Mario Vargas Llosa, Flora Tristán, memoria histórica, feminismo, utopía socialista, igualdad de género

\begin{abstract}
This article analyzes Mario Vargas Llosa's fictional reconstruction of Flora Tristán, taking into account a variety of $19^{\text {th }}$-and $20^{\text {th }}$ - century historical and literary rearticulations. Unlike other writings on the famous Franco-Peruvian author, Vargas Llosa's El paraiso en la otra esquina (2003) articulates a possible and coherent world from an alternative and dissident perspective, without the religiosity, nationalist passion, and paternalistic attitude that we find in other works on Flora Tristán, the intellectual who fought for a socialist utopia of equality for women and the oppressed workers. In order to carry out this historical reconstruction, the critic analyzes Flora Tristán's feminist fabrication in Vargas Llosa's novel, in view of his own essays in regards to the world of fiction and the political power of literature.
\end{abstract}

Keywords: Mario Vargas Llosa, Flora Tristán, historical memory, feminism, socialist utopia, gender equality

\footnotetext{
* Profesor de literatura latinoamericana en la Universidad de Carolina del Norte, en Chapel Hill, y editor de Romance Notes. Ha escrito numerosos artículos en torno al género y la identidad, la memoria histórica, la violencia actual y la otredad. Es autor de $L a$ imaginación novelesca. Bernal Díaz entre géneros y épocas (2009) y de Ser mujer y estar presente. Disidencias de género en la literatura mexicana contemporánea (2014). Es co-autor y editor de Cristina Rivera Garza. Ningún crítico cuenta esto... (2010), Colonial Itineraries of Contemporary Mexico. Literary and Cultural Inquiries (con Anna M. Nogar, 2014) y Senderos de violencia. Latinoamérica y sus narrativas armadas (2015). Es fundador y co-editor de la serie «Palabras de América» en la editorial Albatros.
} 
Mucho tiempo ha pasado desde que don Pío de Tristán y Moscoso, último virrey del Perú, quemara públicamente en Arequipa el libro Pérégrinations d'une Paria (1838), en el que su sobrina Flora denuncia la corrupción y el egoísmo de la clase alta peruana, «su afán de lucro, su amor al poder», «el embrutecimiento de un pueblo» y la inmoralidad que llega «a los últimos peldaños de la jerarquía social» $(3)^{1}$. El episodio ocupa un lugar central en la memoria colectiva del Perú, aquella que a veces le atribuye la quema al arzobispo José Sebastián de Goyeneche y Barreda, o que bien traslada la pira justiciera de Arequipa a Lima (Rodas Rojas 195-199)2 . A partir de entonces la historia de la intelectual y activista franco-peruana Flora Tristán (1803-1844) ha sufrido una serie de transformaciones en diversos tratados biográficos, ficcionales o ensayísticos. Hablo, por ejemplo, de textos tan variados como el ensayo $A l$ margen de un libro olvidado: Flora Tristán en el Perú (1925) de Jorge Basadre o La vie et l'oeuvre de Flora Tristán (1925) de Jules L. Puech; de la crónica Vale un Perú (1939) de Ventura García Calderón, la biografía novelada Flora Tristán. Una mujer sola contra el mundo (1936) de Luis Alberto Sánchez; de la estampa dramática Flora Tristán (1959) de Sebastián Salazar Bondy, o del ensayo feminista Flora Tristán, precursora (1983) de Magda Portal. Gracias a ellos, la imagen que tenemos de Tristán es la de una intelectual que a partir de su propia marginalidad -como hija ilegítima, esposa abusada y separada, o por ser pobre y estar perseguida por su marido y las autoridades- lucha por los derechos de la mujer y los obreros como verdadera precursora del marxismo.

Tomando en cuenta estas rearticulaciones histórico-literarias en las que Flora Tristán es descrita no sólo en términos de su inteligencia, activismo o "profunda vocación feminista» (Portal 21), sino también en base a "su fe y su belleza» (Sánchez, La literatura 1181), "coquetería profesional» (Porras Barrenechea xliv) o "femenina chismografía» (Basadre xviii), en la novela El paraíso en la otra esquina (2003) Mario Vargas Llosa reconstruye su figura paradigmática

1. Cito de la traducción al español de E. Romero del Valle, corregida y revisada por José M. Gómez-Tabanera (1986).

2. En una de sus tradiciones, Ricardo Palma lo confirma, señalando, a propósito de la quema pública del libro satírico Lima por dentro y fuera (1797) en un teatro de Lima: «Y aquí apuntaremos que en los tiempos de la República, por los ańos de 1837 a 1839, se repitió en el mismo proscenio el auto de fe con la obra de Flora Tristán titulada Peregrinaciones de una paria» (712). de una manera alternativa y disidente, sin recurrir a las maniobras de la llamada nueva novela histórica del siglo pasado. Dejando a un lado los consabidos juegos bajtinianos de la heteroglosia, la parodia y el carnaval, el abuso de la metaficción y la excesiva intertextualidad, o las omisiones y los anacronismos con que antańo no pocos autores latinoamericanos distorsionaran el devenir de la historia, Vargas Llosa ubica a Tristán en un mundo posible y coherente, que, pese a su flagrante condición ficcional, se presenta en la página impresa como un trozo completo de una historia real e intimista (Doležel 30-31) . Hábil en la creación de historias que aparentan ser reales y son sólo la contracarátula o el reverso de la realidad, en tanto que representan aquello que no sucedió (Vargas Llosa, Cartas 15), en esta novela el ganador del Premio Nobel de Literatura 2010 toma como materia prima los diarios, las cartas y los manuscritos que Tristán deja inacabados para crear a un personaje auténtico. No hallamos aquí la religiosidad, el fervor nacionalista ni la actitud paternalista de la histórica luchadora social hacia las clases trabajadoras, pero sí el añadido ficcional de un profundo trauma psicológico que trunca su sexualidad y todo lo relacionado a su vida afectiva, en pro de un ideal revolucionario (Kristal 133-134). Gracias a este juego de sugerentes coyunturas entre la historia y la ficción, Vargas Llosa construye nuevas metáforas novelísticas sobre la cultura, el género y la marginación social, como lo hace posteriormente en Travesuras de la niña mala (2006), El sueño del celta (2010), El héroe discreto (2013) y Cinco esquinas (2015). Al hacerlo revalida el poder de la ficción para promover la libertad de pensamiento y expresión, sobre todo al inicio de un nuevo siglo en el que se imponen la diversión y el entretenimiento como valores universales de una civilización entregada al espectáculo, a la literatura y el cine light, al consumo masivo de los bestsellers, o a la apariencia y la frivolidad (Vargas Llosa, La civilización 33-51).

3. En Latin America's New Historical Novel (1993), Seymour Menton analiza con detenimiento diversas novelas históricas latinoamericanas publicadas desde finales de los setenta hasta principios de los años noventa que, por separado y en conjunto, contradicen el curso de la historia valiéndose de los recursos antes mencionados (22-25). También estudian el subgénero de la novela histórica producida en aquellos mismos años Juan José Barrientos, en La nueva novela histórica hispanoamericana (2001), y Fernando Aínsa, en Reescribir el pasado. Historia y ficción en América Latina (2003). 
En términos amplios, El paraíso en la otra esquina narra dos historias paralelas en capítulos intercalados: la de Flora Tristán en la primera mitad del siglo XIX y la de su nieto, el pintor post-impresionista Paul Gauguin, hacia finales del mismo siglo. Lo que une a ambos personajes de la extensa narración es su infatigable búsqueda de un paraíso de justicia y libertad, ya sea una utopía donde no existan divisiones de género y clases sociales (en el caso de Flora), o bien una vida primitiva en Tahití, alejada por completo de la civilización europea (en todo lo referente a Paul $)^{4}$. De esta construcción bipartita, me interesa el delineamiento ficcional de Flora Tristán no sólo porque está hecho con el bagaje de previas reformulaciones históricas sino también porque su «visión utópica ulterior» de algún modo influye en la de su nieto (Habra, «Flora» 105). El personaje de Flora, además, se concibe con la información genética de un «intelectual público» (como su propio creador Vargas Llosa) que tiene un impacto vital en su sociedad porque es capaz de interpretarla, criticarla o moldearla desde cierta posición política, valiéndose de un lenguaje contestatario (De Castro 22-27). Para la crítica Sabine Köllmann, "mucho más fascinantes» son las descripciones novelísticas de Paul Gauguin que los «desesperados intentos de Flora Tristán» por establecer su legitimidad, su brusco rechazo de todo lo relacionado a la sexualidad y su manipulación de ciertos hombres que la encuentran atractiva (246). No creo que el perfil de Tristán justifique este juicio, y a las pruebas me remito.

Si la Flora Tristán que aparece en versiones anteriores es una peregrina romántica que tiene miedo de cruzar el mar para llegar al Perú, una mujer frágil que tiembla y se estremece ante las atenciones del capitán Chabrié, por lo cual «se arropa con su gesto y esconde el rostro entre las manos» (Sánchez, Flora Tristán 10-11), la de Vargas Llosa es todo lo contrario. Tallada a imagen y semejanza de un intelectual poseedor de un lenguaje que intenta, en palabras de Edward Said, decirle verdades al poder, desde una condición solitaria y utilizando las raras oportunidades que tiene de hablar (xvi-xviii), en Elparaiso en la otra esquina Tristán emprende su lucha contra la desigualdad seńalando que "no es cristiano que, en nombre de la santidad de la familia, un hombre se compre una mujer, la convierta en ponedora de hijos,

4. No en vano en un estudio reciente Rosalba Medina Gómez estudia la obra como una complicada y entretejida «búsqueda de la felicidad». en bestia de carga, y, encima, la muela a palos cada vez que se pasa de tragos» (17). Presentándola como «mártir de su propia verdad» (Forgues, «Humanism» 165), Vargas Llosa se centra menos en «la belleza inquietante» que le atribuyera Luis Alberto Sánchez (Flora Tristán 39) y más en el espíritu combativo que le adjudica Sebastián Salazar Bondy, cuando en uno de sus diálogos dramáticos denuncia a voz en cuello que los hombres que han hecho las leyes «han dejado al margen de ellas a la mujer. Y se jactan de civilización» (246). Con una voz íntima que disiente del status quo y se alinea con la de los marginados y menos privilegiados, en la novela de Vargas Llosa, la escritora de Pérégrinations d'une Paria ubica a los lectores en su propio subconsciente, desde donde implora: «¿Hasta cuándo iba a continuar engordando un puñadito de privilegiados gracias a la miseria de la inmensa mayoría? ¿Hasta cuándo la esclavitud, abolida para los hombres, continuaría para las mujeres?» (19).

Gracias a estas intervenciones oportunas, pensadas desde la interioridad de Flora Tristán, los lectores del siglo XXI podemos imaginar a la autora del XIx, quien en su libro Union ouvrière (1843) denuncia la inferioridad de la mujer, su innegable condición de paria, su falta de acción y su escaso acceso al conocimiento. Si bien no deja de ser negativa la designación de "paria», Tristán la subvierte y transforma en paradigma poderoso al homologarla a la mujer mesiánica, y desde un lugar subordinado refuerza su propia persona pública de superioridad moral (Gómez 184-185). Con aquel libro revolucionario, no está de más recordarlo, Tristán se adelanta a su época al denunciar que para las mujeres «no ha habido ninguna función en la Iglesia, ninguna representación frente a la ley, ninguna función en el Estado» $(110)^{5}$. En consonancia con ese espacio ensayístico en el que Tristán acusa la dependencia de las mujeres de sus padres y esposos, equiparando su subordinación y desigualdad a la de los proletarios, en la novela de Vargas Llosa ella actúa como una verdadera activista que busca reformas sociales, «empezando por la igualdad absoluta de derechos para hombres y mujeres» (20). Valiente, decidida e incansable, en esta ficción Tristán trata de convencer a un párroco católico de los beneficios de su proyecto de Unión Obrera; busca a los obreros en los bares para ayudarlos a liberarse de la explotación; y hasta visita

5. Cito de la traducción al español de Yolanda Marco (1977). 
prostíbulos para informarse mejor de las condiciones de vida de las prostitutas, a través de las cuales confirma que el sexo "era uno de los instrumentos primordiales de la explotación y dominación de la mujer» (100). Esta Flora, insisto, mucho se parece a la intelectual orgánica que en la Union ouvrière critica que la mujer no valga nada -o muy poco, en el mejor de los casos- precisamente porque «se la ha educado para ser una graciosa muñeca y una esclava destinada a distraer a su dueño y a servirle» (115, énfasis en el original).

Mucha razón tiene José Miguel Oviedo al constatar, en su lectura de El paraíso en la otra esquina, que Vargas Llosa explota el género de la novela con un espíritu ensayístico, convirtiéndolo en un vehículo reflexivo para meditar, de la forma más íntima y comprometida, sobre aquellos asuntos morales, estéticos e ideológicos que le preocupan como intelectual (73). Si en La utopia arcaica (1996) el ensayista Vargas Llosa ratifica la obligación del escritor «de dar cuenta de las injusticias de su mundo» (26), desplazándose sobre los rieles del compromiso social sin caer en los precipicios de la propaganda barata, distante de sus propios demonios o convicciones interiores, el novelista permite que Flora, Florita, la mujer-mesías o Madame-la-Colére estalle de ira ante el copular salvaje de los hombres, sobre todo por las violaciones nocturnas de su esposo. Mientras la mayoría de sus biógrafos mencionan sus tres embarazos con André Chazal como una parada necesaria en el tormentoso trayecto de su vida -Luis Alberto Sánchez resume el episodio en un par de oraciones: "Hay dos hijos en el hogar sin treguas. Tempestades y berridos; la vida es un ritmo intermitente de ira y tedio» (Flora Tristán 51)-, en la novela de Vargas Llosa, Tristán deshace por completo la idealización del embarazo, como lo hace en la Union ouvrière, al recalcar la esclavitud de la mujer porque está destinada, ab initio, a parir hijos y mantener su condición de "propiedad del marido" (119, énfasis en el original).

Siguiendo esta lógica feminista (defendida en el siglo XX primero por Alfonsina Storni como después por Rosario Castellanos), en El paraiso en la otra esquina, una Flora Tristán demasiado íntima se deja explicar, encolerizada, por un narrador interior que le habla como la voz de su propia conciencia:

...todavía peor que ser copulada, fue quedar embarazada a consecuencia de esos atropellos nocturnos. Peor. Sentir que te hinchabas, deformabas, que tu cuerpo y tu espíritu se trastornaban, sed, mareos, pesadez, el menor movimiento te costaba un esfuerzo doble o triple del normal. ¿Eso las bendiciones de la maternidad? ¿Eso lo que ansiaban las mujeres, con lo que cumplían su vocación íntima? ¿Hincharse, parir, esclavizarse a las crías como si no bastara ser esclavas del marido? (53).

Al definir la preñez como fenómeno que "deforma» -pensemos en el poema «El hijo» de Storni- o como «una enfermedad cuyo desenlace es siempre catastrófico para quien la padece», al decir de Castellanos en Mujer que sabe latín (15), Flora Tristán aparece en la novela armada de un feminismo temprano que se enfrenta a un sistema explotador para subvertir las esferas públicas y privadas de una jerarquía clasista y sexista que oprime de muchas maneras a la mujer y a aquellos grupos que permanecen al margen del poder (Gargallo 32). No sólo eso. A medida que esta exposición de pensamiento se desdobla de un capítulo a otro -gracias al delineamiento certero de la interioridad de Tristán como un ser de "carácter endemoniado» y «espíritu insumiso» (91) - Vargas Llosa prueba novelísticamente aquello que defiende en un ensayo como La tentación de lo imposible (2005): que el verdadero escritor aprovecha hechos históricos y problemas políticos concretos como "pretextos» para denunciar una «injusta realidad presente» o exponer «el anhelo por una sociedad de justicia y fraternidad» (182). Y es que lo más importante, como anota el novelista y ensayista al examinar el trabajo artístico de Victor Hugo en Los Miserables, o como observamos los lectores al cotejar lo que hace Vargas Llosa al reformular, editar, corregir y aumentar diversos retratos histórico-literarios de Flora Tristán en El paraiso en la otra esquina, "no son las semejanzas sino los contrastes, las profundas modificaciones que la imaginación artística ha operado a partir de la visión histórica» (La tentación 184-185).

Flora Tristán es, desde luego, la primera en construir su retrato como el de una mujer que lucha por abolir la esclavitud o servidumbre de las mujeres, por defender el divorcio y por reivindicar la condición de los parias como ella (Peregrinaciones 9-14). Así lo describe no sólo en su primer libro de viajes sino en Promenades dans Londres (1840), en la ya citada Union ouvrière (1843) y en el póstumo Tour de France (1973), donde utiliza su ilegitimidad -como mujer (viajera), representante de la clase obrera, revolucionaria, unionista y feminista- para exigir un drástico cambio social (Schlick 88). Vargas Llosa manipula este retrato "primario" con trazos textuales «secundarios» de su propia cosecha y pensamiento libertario, 
los cuales dotan a Flora Tristán de un carácter indomable y poco convencional en una mujer de principios del siglo XIx. La protagonista de esta novela no sólo busca la utopía social o humanitaria, como se ha dicho en varias ocasiones (Oviedo 74; Castillo Uculmana 251-255), sino que la fabrica y pule al costo que sea a través de diversos actos, pensamientos y palabras manipulados, por supuesto, por la imaginación de Vargas Llosa.

Esto se observa en la novela desde que Flora, en vez de contener sus impulsos, según el consejo de su abogado, le rompe a su marido un plato de cerámica en la cabeza para robarse a su hija Alina; cada vez que se inventa nuevas identidades, presentándose como virgen o viuda, o escondiendo su maternidad; cuando denuncia al padre de su hija por violación e incesto; al darle falsas esperanzas al capitán Chabrié sólo para que éste le consiga un certificado que documente la legitimidad de su nacimiento; o cuando se viste de hombre en Londres durante cuatro meses "para moverse con libertad y realizar sus investigaciones sociales» (235). Gracias a estos y otros actos transgresivos en los que Tristán repudia a su poderoso tío porque le niega la herencia de su padre, o insulta a los hombres de poder por ser enemigos de la clase obrera, o critica a los «indios, zambos [y] mestizos» que en cualquier conflicto civil se prestan "a ser carne de cañón, instrumento de luchas de facciones que no tenían nada que ver con su suerte» (302), Flora exclama, "que la esclavitud [es] una aberración humana, un crimen contra la civilización, y que, tarde o temprano, también en el Perú se aboliría» (323). Sintiéndose portadora absoluta de un conocimiento divino, como si verdaderamente hubiera sido «elegida por el cielo para desempeñar su misión» (Jourdan 228-229), Flora, en calidad de mujer-mesías, por voluntad propia clausura las puertas de su sexualidad como estrategia máxima para alcanzar el paraíso.

El mismo Paul Gauguin reconoce en la novela el perfil revolucionario y anarquista de su abuela mientras busca su libertad en Tahití. La admira por dejar todo atrás para encontrarse a sí misma y conquistar el mundo, aun cuando el precio fuera muy alto. El narrador, instalado en su conciencia, imagina a Flora Tristán decidida a todo con tal de salvar a su hija de las garras de su ex marido que sólo quiere aprovecharse de su supuesta herencia tras el viaje al Perú: «La fría discusión, los reproches, los gritos. Y, de pronto, la magnífica abuela reventándole un florero, ¿una olla, una silla?, a Chazal en la cabeza, y, aprovechando la confusión, tomando a Aline de la mano y escapando con ella por las calles desiertas y empapadas de Versalles» (163). Paul no renuncia, como ella, a la sexualidad pero sí al amor, tal vez siguiendo su ejemplo, aunque sólo fuera de manera inconsciente. "En 1888», le señala a Paul una voz interior, «ya habías llegado a la conclusión de que el amor, a la manera occidental, era un estorbo, que, para un artista, el amor debía tener el exclusivo contenido físico y sensual que tenía para los primitivos, no afectar los sentimientos, el alma» (290).

$\mathrm{Si}$ en las primeras décadas del siglo pasado Luis Alberto Sánchez retrata a Flora «privada de entregarse al amor» debido sobre todo al fracaso conyugal (La literatura 1179), a principios del 2000 Vargas Llosa da un paso mucho más atrevido en su caracterización de Tristán. Para satisfacer a los lectores que, al decir del novelista peruano, acuden a la literatura para encontrar ideas prohibidas, informaciones escamoteadas entre líneas o protestas y condenas impedidas (La tentación 221), Flora se niega el derecho a explorar su sexualidad. En total oposición al nieto que en Tahití encontrará la libertad en su nueva estética pictórica y explorando su sexualidad con jóvenes de ambos sexos, Flora rechaza cualquier posibilidad de cercanía íntima. Cuando en el Perú el coronel Bernardo Escudero le declara su amor y la besa, su voz interna la sacude por completo: «iNo, no, Dios mío, qué locura! ¡Nunca, nunca! ¿Volver a aquello? ¿Sentir, en las noches, que un cuerpo velludo, sudoroso, se montaba sobre ti y te cabalgaba como a una yegua? ... ¡Ni por todo el oro del mundo, Florita!» (315).

Algo parecido sucede cuando el artista Jules Laure, después de pintar su retrato la enamora, y ella lo desarma argumentando que «su misión, su lucha, eran incompatibles con una pasión amorosa. Ella, para dedicarse en cuerpo y alma a cambiar la sociedad, había renunciado a la vida sentimental» (367). El disgusto y la repugnancia que el sexo le inspiran parece disiparse un tiempo después en los brazos de su amante Olympia Maleszewska, con quien descubre «el placer físico, de un goce sin violencia, entre iguales» (397). Pero también a ella la despacha sin remordimientos después de dos años de ardiente pasión, objetando: «tengo una misión. No podría cumplirla con mis sentimientos y mi mente divididos entre mis obligaciones y tú. Lo que voy a hacer exige que nada ni nadie me distraiga. Ni siquiera tú. Debo entregarme en cuerpo y alma a esta tarea» (398). En episodios como éstos, Flora construye a cinceladas su utopía rechazando cualquier tipo de amor físico y exaltando el amor espiritual como único y posible 
camino libertario. Su incomodidad física con los hombres y su rompimiento abrupto con Olympia mucho tienen que ver con los traumas psicológicos ocasionados por el marido o por el desamparo de su propia madre, pero sobre todo reflejan, a manera de tesis personal, que "la revolución se ha convertido en un valor supremo, en su razón de existir» (Parrilla Sotomayor 331).

Al retratar ambos extremos utópicos, el de Paul y el de Flora, enfatizando la aberración que cada uno siente hacia el amor o el sexo, respectivamente, Vargas Llosa confirma una de sus mayores preocupaciones como pensador: la indagación del proceso imaginativo de la mente creadora y de las pasiones individuales que promueven la recreación estética, literaria, intelectual (Habra, Mundos alternos 178). Lo mejor de esta estructura contrapuntística es que ataca varios frentes a la vez. No sólo recrea, por ejemplo, la consabida tensión entre lo masculino y lo femenino, o entre el arte y la política sino el perfil político de una intelectual que realiza importantes contribuciones a la emancipación de las mujeres, o bien la sensibilidad artística de un hombre que revoluciona el arte de su época (Henighan 379). Mucha distancia, en este sentido, es la que separa a esta Flora Tristán de aquella retratada por Carolina Freire de Jaimes en 1875, en su discurso de ingreso al Ateneo de Lima. Cierto es que en aquel escrito del siglo XIX Freire de Jaimes, al examinar la escritura de Tristán en Pérégrinations d'une Paria, la llama «brillante escritora» (19), en vista de sus "cuadros completos de una admirable exactitud» (20). Pero su patriotismo y extrema religiosidad -hay que decirlo- no le permiten ver el alcance político de las ideas de Tristán. Producto de su época, Freire de Jaimes no sabe cómo excusar "lo virulento de sus apreciaciones respecto del Perú» (37) y le critica, sobre todo, que no haya podido «dejar de tomar ese carácter de dogmatismo, de presunción reformadora que le quita gran parte de su amenidad» (43).

Aquella Flora de «inteligencia herida» (43), simultáneamente admirada y criticada por Freire de Jaimes, poco tiene que ver con la agencia política de aquella que hallamos, transformada por la imaginación novelística, en El paraiso en la otra esquina. Aquí Flora es una mujer que lucha por su libertad y por la de otras y otros a su alrededor. A Madame de Pierreclos, una joven viuda que se pasa días enteros llorando por el marido ausente, le pide, por ejemplo, que no se entierre en vida y que haga algo útil para la humanidad: "Estudie, haga el bien, ayude a los millones de seres que, ellos sí, padecen problemas muy reales y concretos, el hambre, la enfermedad, el desempleo, la ignorancia, y no pueden hacerles frente. Lo suyo no es un problema, es una solución. La viudez la salvó de tener que descubrir la esclavitud que significa el matrimonio para una mujer» (95). Transgresora a cuál más, Flora desdeña la posibilidad de vivir una vida "novelesca» y construye para sí -y por extensión para otras mujeres de su condición- una vida «más real» (Rodríguez Mansilla 428). Por eso le insiste a la viuda: «No juegue a sentirse una heroína de novela romántica. Siga mi consejo. Regrese a la vida y ocúpese de cosas más generosas que cultivar su dolor. Por último, si no quiere dedicar su tiempo a hacer el bien, goce, diviértase, viaje, consígase un amante» (95).

En otra ocasión, cuando visita La Antigualla, un hospital para locos y prostitutas en Lyon, Flora se enfurece al escuchar de uno de los doctores que en la mayoría de los casos el hambre y la miseria han causado la enajenación de todos esos hombres y mujeres. Enérgica, como en todos sus escritos, Flora le da la razón, no sin antes tratar de despertar su conciencia con respecto al verdadero problema que nadie quiere denunciar: «Lógico, doctor. ¿¿Sabe usted cuánto gana una obrera, en Lyon, por catorce o quince horas en el taller? Cincuenta centavos. La tercera o cuarta parte que el obrero, por el mismo trabajo. ¿Quién vive con eso al día, si tiene hijos que alimentar? Por eso muchas recurren a la prostitución, y acaban locas» (103). Su razonamiento ficcional guarda un cercano parecido con el espíritu combatiente de sus escritos históricos, aquellos en los que no se cansa de denunciar la inferioridad de la mujer doblegada por el abuso doméstico, los embarazos y la miseria que, según ella, es la responsable de lanzar a muchas «desgraciadas» a la prostitución (Unión Obrera 123). En ambos casos, tanto en la novela contemporánea como en la vida tormentosa que le tocó vivir en el siglo XIX, Flora Tristán busca la igualdad entre hombres y mujeres, lucha contra la opresión económica de la clase trabajadora e intenta abolir el maltrato generalizado contra las mujeres (Gutiérrez Mouat 399). En ambos casos, valga la insistencia, su voz es signo de disidencia y rebeldía. Es la voz de la activista comprometida que escribe en uno de sus libros: «La inferioridad de la mujer, una vez proclamada y dada como principio, ved qué consecuencias desastrosas ocasiona para el bienestar universal de todos y de todas en la humanidad» (Unión Obrera 115, énfasis en el original).

Esta misma Flora Tristán que aparece en El paraiso en la otra esquina se transforma durante el 
largo trayecto de Europa al Perú. Al pasar por la isla de Cabo Verde, por ejemplo, palpa de cerca la esclavitud y se muestra, como en Pérégrinations d'une Paria, asqueada ante el espectáculo de los negros que son comprados y vendidos como animales de trabajo. Aquí, como en su libro de 1838, su socialismo, aquél que en gran medida proviene del socialismo utópico francés de 1830, que conserva los ideales de la Revolución Francesa -libertad, igualdad y fraternidad- y que busca, a diferencia de la teoría socialista anterior al marxismo, la libertad de las mujeres (Gómez 181), no la salva del racismo de su época. Por esa razón Tristán describe sin reparo alguno, tanto en su libro como en la ficción, el «olor a negro, que no puede compararse con nada, que da náuseas y que persigue por todas partes» (180). Sólo que esta vez, desde el siglo XXI, Flora Tristán tiene la oportunidad de enmendar su error, gracias a un narrador que le habla desde lo más profundo de su ser:

¡Olor a negro! Cuánto habías lamentado después esa imbecilidad frívola, que repetía un lugar común de los esnobs parisinos. No era el "olor a negro" lo repugnante en aquella isla, sino el olor a la miseria y la crueldad, al destino de esos africanos al que los mercaderes europeos habían convertido en materia de injusticia, todavía eras una ignorante cuando escribiste las Peregrinaciones de una paria (180).

La enmienda ficcional no cambia, desde luego, el racismo del siglo XIX, del cual no puede escapar Flora Tristán. Pero el pasaje nos invita a revisar, desde un presente racista y discriminatorio, cómo la «blanquitud» se consolida como «necesidad» y «codeterminante de la identidad moderna» (Echeverría 61) ${ }^{6}$.

Durante su paso por el Perú, a Flora Tristán también la impresiona la valentía de las rabonas, las mujeres que van con los soldados a los campos de batalla para satisfacer sus necesidades sexuales, proveerlos de alimentos y participar en actividades

6. Bolívar Echeverría explica la «blanquitud» a la que me refiero aquí como un rasgo identitario civilizatorio que se consolida entre los siglos XV y XVIII tomando como modelo la apariencia étnica de la población europea noroccidental. Por eso mismo, arguye el filósofo ecuatoriano, el ser «moderno» busca pertenecer «de alguna manera o en cierta medida a la raza blanca y consecuentemente a relegar en principio al ámbito impreciso de lo pre, lo anti o lo no-moderno (no humano) a todos los individuos, singulares o colectivos, que fueran "de color" o simplemente ajenos, "no occidentales"» (61). militares si hay oportunidad de hacerlo (Miseres, «Republic» 29) ${ }^{7}$. Esas mujeres de origen indígena o mestizo cautivan su atención por su abnegación y total entrega, porque van armadas y administran su cuerpo como les place. Al menos así lo registra Tristán en Pérégrinations d'une Paria:

Las rabonas no son casadas, no pertenecen a nadie y son de quien ellas quieren ser. Son criaturas al margen de todo. Viven con los soldados, comen con ellos, se detienen en donde ellos acampan, están expuestas a los mismos peligros y soportan aún mayores fatigas. Cuando el ejército está en marcha, es casi siempre del valor y de la intrepidez de estas mujeres que lo preceden de cuatro a cinco horas, de lo que depende su subsistencia. Cuando se piensa en que, además de llevar esta vida de penurias y peligros cumplen los deberes de la maternidad, se admira uno de que puedan resistir. Es digno de notar que, mientras el indio prefiere matarse antes de ser soldado, las mujeres indias abrazan esta vida voluntariamente y soportan las fatigas y afrontan los peligros con un valor de que son incapaces los hombres de su raza (276).

En consonancia con estas observaciones, en la novela del 2003 Tristán refleja una admiración similar por las rabonas. Porque en calidad de esposas, concubinas o amantes son la fuerza del campamento militar. En una de sus conversaciones con el coronel Althaus, una Flora ficcional llega a las mismas conclusiones que la Flora real, señalando, entre otras particularidades, su excepcional capacidad para el trabajo, compitiendo con los hombres, e incluso superándolos:

Cavaban trincheras, levantaban parapetos, cocinaban para sus hombres, les lavaban las ropas, los espulgaban, hacían de mensajeras y vigías, de enfermeras y curanderas, y servían para el desfogue sexual de los combatientes cuando a éstos se les antojaba. Muchas de ellas, pese a estar embarazadas, seguían trabajando a la par que las otras, seguidas por desarrapadas criaturas (277).

A todas vistas, la reivindicación que Flora Tristán realiza de las rabonas en su libro de viaje refleja una

7. Como bien señala Juan Quintana, se les llamaba «rabonas» porque ocupaban el «rabo» (o la cola) del Ejército (aun sin estar legalmente afiliadas a él); suyo era el último lugar en las caravanas militares (66). 
calculada perspectiva de género, con la cual intenta mostrar que es posible la igualdad entre hombres y mujeres, que el modelo no está en Europa (donde ella misma ha sufrido la opresión) y, sobre todo, que vale la pena seguir luchando por los derechos de la mujer (Miseres, «Las últimas» 194). Que Vargas Llosa rearticule esta postura de género en la ficción no es poca cosa. A través de ella recalca el afán real de Tristán de alcanzar una utopía social y colectivista de unión entre la mujer y los oprimidos del mundo entero (Forgues, «Destino» 100). Pese a todos sus prejuicios y limitaciones, el perfil de Flora en la novela es el de una mujer que habla por otras; sustenta su pensamiento utópico con respecto a la libertad de los hombres con ejemplos concretos del mundo real, y además utiliza su escritura para defender a los oprimidos.

En Pérégrinations d'une Paria Flora Tristán realiza una hazaña feminista semejante con la figura de Doña Francisca Zubiaga, esposa del presidente Agustín Gamarra y apodada «La Mariscala». Para Tristán «Doña Pancha» es «una mujer excepcional, tan extraordinaria por el poder de su voluntad como el gran alcance de su inteligencia» (Peregrinaciones 418). La retrata en su libro como la más entregada de todos los soldados, recorriendo los campos de batalla vestida de hombre, montando a caballo, visitando cuarteles y campamentos; como una mujer superior e indomable. Tristán reconoce en Doña Pancha no a una Primera Dama sino a una Presidenta, una mujer capaz de pasar por encima de la autoridad de su esposo para servir mejor a su patria. No en vano Ricardo Palma retrata en sus Tradiciones Peruanas a Doña Pancha siempre al frente de la tropa, reconociendo la sagacidad de la escritora franco-peruana al reflejarla como una mujer fuera de serie. "A la cabeza del ejército, y en traje militar», escribe el tradicionista, «iba doña Francisca Zubiaga, la esposa de Gamarra, mujer que tan importante papel desempeñó en la política de aquellos tiempos y a la que, con muy caprichosos colores, nos ha pintado Flora Tristán en sus Peregrinaciones de una paria» (1062, el énfasis es mío). Curiosamente, estos matices con los que Tristán plasma el retrato de Doña Pancha son los que más repulsión le causan a Carolina Freire de Jaimes, aunque los entiende por provenir «de un cerebro enfermo" o de la ambición que obnubila a la escritora que quiere ganarse un certificado de legitimidad y no lo consigue (34-35). Para Freire de Jaimes, la esposa de Gamarra es, por encima de todo, sólo eso: una esposa fiel, una incondicional compañera, un apoyo y nada más: «Gamarra fue un mandatario íntegro, inteligente y enérgico; no como lo supone Flora Tristán, un ser débil, dominado por su varonil esposa y descargando en ella todo el peso de la administración pública. Si Gamarra escuchó alguna vez la opinión de su compañera, fue como el consejo que se recibe de un amigo, como la inspiración del ser interesado en nuestra dicha» (34).

Situándose a buena distancia de esta percepción negativa, en El paraíso en la otra esquina Vargas Llosa le adjudica a "La Mariscala» la misma militancia, valentía y don de mando con que la retrata Tristán en Pérégrinations d'une Paria. En la novela la voz narrativa muestra a Doña Francisca Zubiaga gobernando con mano de hierro y sin titubeos: "Cuando Gamarra ocupó la presidencia, tuvo tanta o más autoridad que el Mariscal en los asuntos de gobierno y no vaciló en sacar la pistola para imponerse, y en manejar el látigo o abofetear a quien no le obedecía o guardaba respeto, como hubiera hecho el más beligerante varón» (273). Esta figura aguerrida y decidida a todo -le señala a Flora la voz de su concienciale da el valor para transformarse en un ser libre y resuelto, tanto o más que cualquier hombre. Por eso mismo Doña Pancha ocupa un lugar preferencial en la ficción de Vargas Llosa, no como un reflejo fiel de lo que escribe Tristán en su libro pero sí como un retrato convincente, posible y verosímil, a pesar de haber sido corregido y aumentado por la mano del autor contemporáneo:

Se hizo famosa por su excelente puntería. Durante el conflicto con Bolivia, fue ella, al frente de la tropa, con su osadía ilimitada y su coraje temerario, la vencedora de la batalla de Paria. Luego de la victoria, festejó con sus soldados bailando huaynos y bebiendo chicha. Hablaba con ellos en quechua y sabía carajear. A partir de entonces, su influencia sobre el general Gamarra fue total. En los tres años que éste ocupó la presidencia del Perú, el verdadero poder lo ejerció doña Pancha. Se le atribuían intrigas y crueldades inauditas contra sus enemigos, pues su falta de escrúpulos y de freno eran tan grandes como su valor. Se decía que tenía muchos amantes y que, alternativamente, los mimaba o maltrataba como si fueran muñequitos, perros falderos (312-313).

Imposible saber si así fue, realmente, Doña Francisca Zubiaga de Gamarra. Pero que Vargas Llosa la muestre con estas tonalidades, inspirado por el libro de Tristán, no sólo confirma el feminismo temprano de la franco-peruana -tan avanzada para su época como 
la misma Doña Pancha-, sino la posibilidad de ser una mujer libre e independiente, artesana de su propio destino -en los campos de batalla, en la política o en el mundo de las letras- tanto en el siglo XIX como en un presente aún dominado por la desigualdad de género. En uno y otro caso, en el libro de viaje y en la novela, el mensaje con respecto a la igualdad de género se impone por encima de cualquier otro. «Había, pues, mujeres», le dice a Flora su narrador interior, «que no se dejaban humillar, ni tratar como siervas, que conseguían hacerse respetar. Que valían por sí mismas, no como apéndices del varón, incluso a la hora de manejar el látigo o disparar pistolas» (313-314).

El final de Flora Tristán en la novela es y no es el de las otras. En El paraíso en la otra esquina Flora también muere en Burdeos a los cuarenta y un años después de un largo padecimiento por una bala que el ex marido le deja incrustada en el pecho en un atentado público. La autora de Pérégrinations d'une Paria es víctima de una fulminante fiebre tifoidea que le causa una congestión cerebral. Su retrato final, sin embargo, ya no es el perfil casi místico de «Pasión y muerte» con el que otros biógrafos la despiden histórica o literariamente del mundo (Sánchez, Flora Tristán 221). Esta vez, Flora muere en su ley:

Lo habías hecho, Florita. Pese a la bala junto al corazón, a tus malestares, fatigas, y a ese ominoso, anónimo mal que te minaba las fuerzas, lo habías hecho en estos ocho últimos meses. Si las cosas no habían salido mejor no había sido por falta de esfuerzo, de convicción, de heroísmo, de idealismo. Si no habían salido mejor era porque en esta vida las cosas nunca salían tan bien como en los sueños (459).

Colocando estas palabras en el inconsciente de Flora Tristán, Vargas Llosa confirma su propio perfil y el de su protagonista como el de dos intelectuales que lo arriesgan todo para prestar un servicio altruista a la humanidad. El último mensaje de Flora es el de una pensadora que articula hasta sus últimas consecuencias una serie de puntos de vista e ideologías que podrían funcionar en su sociedad, aun cuando su posición siga siendo marginal, como verdadera exiliada, outsider, o amateur social (Said 110). Digo que este pasaje reivindica la intelectualidad de ambos porque, al leer a Tristán, también escuchamos a Vargas Llosa, el pensador que en numerosos ensayos sigue justificando su quehacer literario, el potencial subversivo de la literatura, precisamente porque contiene un a priori político. Porque en los libros, señala el Nobel en La civilización del espectáculo, como si rearticulara de nueva cuenta la voz de Tristán:

...aprendí que el mundo está mal hecho y que estará siempre mal hecho -lo que no significa que no debamos hacer lo posible para que no sea todavía peor de lo que es-, que somos inferiores a lo que soñamos y vivimos en la ficción, y que hay una condición que compartimos, en la comedia humana de la que somos actores, que, en nuestra diversidad de culturas, razas y creencias, hace de nosotros iguales y debería hacer, también, solidarios y fraternos (217).

Podemos o no estar de acuerdo con este postulado, pero tanto aquí como en la novela, el autor y $\mathrm{su}(\mathrm{s})$ protagonista(s) van de la mano del infierno al paraíso, demostrando de múltiples maneras que la función máxima del intelectual es poder articular un mensaje, una actitud, una filosofía por y para un público, aun cuando sus ideales de verdad, justicia, libertad o igualdad no parezcan propios de este mundo (Said 5-11). Desde luego, no será ésta la última rearticulación artística de Flora Tristán. En el 2011, por ejemplo, apareció el cortometraje Flora de Lorena Stricker, "documental ensayo» ganador del Premio María Luisa Bemberg, otorgado por la Asociación La Mujer y el Cine en Buenos Aires. También ese mismo año la serie Mujeres malditas, de Radiotelevisión Española (RTVE), le dedicó todo un capítulo a la pensadora franco-peruana. Desde entonces su vida continúa debatiéndose en diversos medios virtuales. Tal vez porque su lucha por la igualdad de las mujeres - ¿hace falta decirlo?- sigue siendo la de muchas que aún en el siglo xxi permanecen al margen del poder, a las orillas del conocimiento, aunque hoy los discursos de exclusión sean más sutiles o "políticamente correctos».

\section{Bibliografía}

Aínsa, Fernando. Reescribir el pasado. Historia y ficción en América Latina. Mérida, Venezuela: Centro de Estudios Latinoamericanos «Rómulo Gallegos»/ Ediciones El otro, el mismo, 2003.

BARRIENTOS, Juan José. La nueva novela histórica hispanoameriana. México: Universidad Nacional Autónoma de México, 2001.

BASADRE, Jorge. «Introducción». Emilia Romero (trad.). Peregrinaciones de una paria. Flora Tristán. Lima: Cultura Antártica, 1946: i-xxiii. 
Castellanos, Rosario. Mujer que sabe latín... México: Fondo de Cultura Económica, 2007.

Castillo Uculmana, Patricia. «Las utopías en El paraíso en la otra esquina. Acercamiento a Flora Tristán y Paul Gauguin». Miguel Ángel Rodríguez Rea (ed.). Mario Vargas Llosa y la critica peruana. Lima: Universidad Ricardo Palma / Editorial Universitaria, 2011: 249-256.

De Castro, Juan E. Mario Vargas Llosa. Public Intellectual in Neoliberal Latin America. Tucson: The University of Arizona, 2011.

Doležel, Lubomír. Possible Worlds of Fiction and History. The Postmodern Stage. Baltimore: The Johns Hopkins UP, 2010.

Echeverría, Bolívar. Modernidad y blanquitud. México: Era, 2010.

Forgues, Roland. «Destino y utopía, absurdo y condición humana y su traducción en El paraiso en la otra esquina». Roy C. Boland Osegueda e Inger Enkvist (eds.). Una pasión por la literatura. Estudios criticos sobre Mario Vargas Llosa. Vol 2. Jannali, NSW: Antípodas Monographs, 2007: 97-105.

Forgues, Roland. "Humanism and Criticism: The Presence of Frenche Culture in Vargas Llosa’s Utopia». Juan E. De Castro and Nicholas Birns (eds.). Vargas Llosa and Latin American Politics. New York: Palgrave Macmillan, 2010: 159-169.

Freire de Jaimes, Carolina. "Flora Tristán”. Apuntes sobre su vida y sus obras». Anales de la Sección de Literatura. 1875-1876. Lima: Imprenta del Universo, de Carlos Prince, 1876: 12-46.

Gargallo, Francesca. Ideas feministas latinoamericanas. México: Universidad de la Ciudad de México, 2004.

GómEz, Leila. «Mujer sin equipaje. El viaje de Flora Tristán al Perú». Revista de Critica Literaria Latinoamericana, 80, (2014): 169-86.

GutiÉrrez Mouat, Ricardo. "Cosmopolitismo y hospitalidad en El paraíso en la otra esquina, de Mario Vargas Llosa». MLN, 123, (2008): 396-414.

HaBra, Hedy. «Flora Tristán: de aventurera a visionaria en El paraiso en la otra esquina». Alba de América, 55-56, (2010): 105-120.

Habra, Hedy. Mundos alternos y artísticos en Vargas Llosa. Madrid: Iberoamericana / Vervuert, 2012.

Henighan, Stephen. «Nuevas versiones de lo femenino en La Fiesta del Chivo, El paraiso en la otra esquina y Travesuras de la niña mala». Hispanic Review, 77.3, (2009): 369-388.

Jourdan, Jean-Paul. «Flora Tristán entre novela, historia y memoria». Valérie Joubert Anghel (trad.). Elvire Gomez-Vidal Bernard (ed.). El universo de Mario Vargas Llosa y sus resonancias / L'univers de Mario Vargas
Llosa et ses resonances. Pessac: Presses Universitaires de Bordeaux, 2011: 223-247.

Köllmann, Sabine. A Companion to Mario Vargas Llosa. Rochester: Tamesis, 2014.

KristaL, Efraín. «From Utopia to Reconciliation: The Way to Paradise, The Bad Girl and The Dream of the Celtr. Efraín Kristal and John King (eds.). The Cambridge Companion to Mario Vargas Llosa. Cambridge: Cambridge UP, 2012: 129-147.

Medina Gómez, Rosalba. «La búsqueda de la felicidad en El paraíso en la otra esquina de Mario Vargas Llosa.» Espéculo, 47, (2011).

Menton, Seymour. Latin America's New Historical Novel. Austin: U of Texas P, 1993.

Miseres, Vanesa. «Las últimas de la fila: representación de las rabonas en la literatura y cultura visual decimonónica». Revista de Crítica Literaria Latinoamericana, 80, (2014): 187-206.

Miseres, Vanesa. «On a Republic in Ruins: Flora Tristan’s Peregrinations of a Pariah and the Role of the Rabonas in Nineteenth-Century Peru». Review: Literature and Arts of the Americas, 84, (2012): 29-36.

Oviedo, José Miguel. Dossier Vargas Llosa. Lima: Taurus, 2007.

Palma, Ricardo. Tradiciones Peruanas. Edith Palma (ed. y prólogo). Madrid: Aguilar, 1968.

Parrilla Sotomayor, Eduardo E. «La búsqueda de la utopía y el conflicto ideológico en la novela de Vargas Llosa». Pol Popovic Karic y Fidel Chávez Pérez (eds.). Mario Vargas Llosa: Perspectivas críticas. Ensayos inéditos. México: Miguel Ángel Porrúa y Tecnológico de Monterrey, 2010: 315-363.

Porras Barrenechea, Raúl. «El paisaje peruano. De Garcilaso a Riva-Agüero». José de la Riva-Agüero (ed.) Paisajes peruanos. Lima: Santa María, 1955: vi-clxii.

Portal, Magda. Flora Tristán, precursora. Lima: La Equidad, 1983.

QUiNTANA, Juan. «Las rabonas: género y estigma social en el ejército a fines del siglo XIX». Historias. Revista de la Coordinadora de Historia, 1, (1997): 63-67.

Rodas Rojas, Luz Stella. Flora Tristán: devenir escritura, devenir mujer. Medellín: Todográficas, 2008.

Rodríguez Mansilla, Fernando. "Los conceptos de novela e historia en El paraiso en la otra esquina (con una coda a propósito de El sueño del celta)». Anales de Literatura Hispanoamericana, 43, (2014): 419-437.

SAID, Edward W. Representations of the Intellectual. New York: Vintage, 1996.

Salazar Bondy, Sebastián. «Flora Tristán. Estampa dramática en tres actos». Obras de Sebastián Salazar Bondy. Tomo II. Piezas Dramáticas. Lima: Moncloa Editores, 1967: 241-281. 
SÁnchez, Luis Alberto. Flora Tristán. Una mujer sola contra el mundo. Lima: Mosca Azul Editores, 1987.

SÁnchez, Luis Alberto. La literatura peruana. III. Lima: EMISA editores, 1989.

Schlicк, Yaël. Feminism and the Politics of Travel after the Enlightenment. Lewisburg: Bucknell UP, 2012.

STORNI, Alfonsina. «El hijo.» Orlando Gómez-Gil (ed.). Literatura hispanoamericana. Antología critica. Vol 2. New York: Holt, Rinehart and Windston, 1971: 256.

Tristán, Flora. Peregrinaciones de una paria. E. Romero del Valle (trad.). José M. Gómez-Tabanera (ed.). Gijón, Asturias: Ediciones Istmo, 1986.
Tristán, Flora. Unión Obrera. Yolanda Marco (ed. y trad.). Barcelona: Editorial Fontamara, 1977.

VARgas Llosa, Mario. Cartas a un novelista. Buenos Aires: Ariel, 1997.

Vargas Llosa, Mario. El paraíso en la otra esquina. Bogotá: Alfaguara, 2003.

Vargas Llosa, Mario. La civilización del espectáculo. Madrid: Alfaguara, 2012.

Vargas Llosa, Mario. La tentación de lo imposible. Victor Hugo y Los Miserables. México: Alfaguara, 2005.

Vargas Llosa, Mario. La utopía arcaica. José María Arguedas y las ficciones del indigenismo. México: Fondo de Cultura Económica, 1996. 